\title{
MicroRNA 399 as a potential integrator of photo-response, phosphate homeostasis, and sucrose signaling under long day condition
}

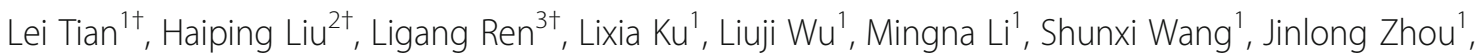 \\ Xiaoheng Song ${ }^{1}$, Jun Zhang ${ }^{4}$, Dandan Dou' ${ }^{1}$, Huafeng Liu', Guiliang Tang ${ }^{2^{*}}$ and Yanhui Chen ${ }^{1 *}$ (D)
}

\begin{abstract}
Background: Photoperiod-sensitivity is a critical endogenous regulatory mechanism for plant growth and development under specific environmental conditions, while phosphate and sucrose signaling processes play key roles in cell growth and organ initiation. MicroRNA399 is phosphate-responsive, but, whether it has roles in other metabolic processes remains unknown.

Results: MicroRNA399 was determined to be sucrose-responsive through a microRNA array assay. High levels of sucrose inhibited the accumulation of microRNA399 family under phosphate starvation conditions in Arabidopsis thaliana. Similarly, exogenous sucrose supplementation also reduced microRNA399 expression in maize at developmental transition stages. RNA sequencing of a near-isogenic line(photoperiod-sensitive) line and its recurrent parent Huangzao4, a photoperiod-insensitive line, was conducted at various developmental stages. Members of microRNA399 family were down-regulated under long-day conditions in the photoperiod-sensitive near-isogenic line that accumulated more sucrose in vivo compared with the control line Huangzao4.
\end{abstract}

Conclusion: MicroRNA399s may play central roles in the integration of sucrose sensing and photoperiodic responses under long day conditions in maize.

Keywords: microRNA399, Sucrose., Maize., Arabidopsis thaliana., Photoperiod., Long day.

\section{Background}

Maize originated in southern Mexico in a tropical environment and required post-domestication selection to adapt to temperate ecological zones. Short-day-requiring tropical, but not temperate, maize shows a prevenient sensitivity response to a long photoperiod [1, 2]. Consequently, decreasing the sensitivity of photoperiodic regulation is an effective way to obtain new maize varieties. In Arabidopsis thaliana, numerous genes that are implicated in the control of the plant circadian clock and photoperiodicity

\footnotetext{
* Correspondence: gtang1@mtu.edu; chy9953@163.com

${ }^{\dagger}$ Lei Tian, Haiping Liu and Ligang Ren contributed equally to this work. ${ }^{2}$ Department of Biological Sciences, Michigan Technological University, Houghton, MI 49931, USA

${ }^{1}$ College of Agronomy, National Key Laboratory of Wheat and Maize Crop

Science, Henan Agricultural University, Zhengzhou 450002, China

Full list of author information is available at the end of the article
}

have been extensively studied to dissect the molecular mechanism of flowering regulation [3-6]. In maize, however, only a small number of genes, such as Zea mays CENTRORADIALIS1 (ZCN1), ZCN8, and as well as the CONSTANS-like gene CONZL, have been associated with the vegetative-to-reproductive phase transition and flowering time [7-9]. ZmCCT, which encodes a CCT domaincontaining protein, is an important gene related to photoperiodic flowering [10]. Teosinte $Z m C C T$ alleles are consistently expressed at higher level than temperate maize alleles under long day (LD) condition [11]. In our previous studies, by generating the populations from a cross between the temperate inbred line Huangzao4 ( $\mathrm{H} 4$, the recurrent parent) and the tropical inbred line CML288 (the donor parent), we mapped qDPS10 to a 130-kb region and by the bioinformatics analysis. The CCT domain gene

(C) The Author(s). 2018 Open Access This article is distributed under the terms of the Creative Commons Attribution 4.0 International License (http://creativecommons.org/licenses/by/4.0/), which permits unrestricted use, distribution, and 
(GRMZM2G381691) in qDPS10 was considered as a candidate gene for photoperiod sensitivity. Additionally, higher transcript levels were observed in the ZmCCT-associated near-isogenic line (NIL), than that in its recurrent parent, H4 under LD conditions [12].

In addition, circadian rhythms are influenced by environmental signals, such as light and temperature, and by endogenous sugar production from photosynthesis to enable plants to adapt to local environments [13, 14]. Sucrose, the major type of sugar produced by photosynthesis in plants, is a pivotal energy and carbon resource for plants. Sucrose also acts as a central sensing and signaling molecule in plant metabolic pathways [15-19] and is the main form of sugar transported from mature leaf mesophyll cells to roots, stems, and other organs. High levels of endogenous sucrose repress photosynthesis and nutrient mobility $[20,21]$.

MicroRNAs (miRNAs) are endogenous, non-coding, single-stranded small RNAs approximately 21-24 nucleotides long. Many miRNAs regulate flowering time in various species by cleaving or repressing the translation of their target mRNAs [22-27]. In A. thaliana, miR156 and its target SQUAMOSA PROMOTER BINDING PROTEIN-LIKE (SPL) genes constitute an endogenous flowering pathway, and SUPRESSOR OF OVEREXPRESSION OF CONSTANS1 (SOC1) and FLOWERING LOCUS $\mathrm{T}(F T)$ can directly bind to the promoter regions of SPL3, SPL4, and SPL5 and regulate them in a photoperiod-dependent manner [28]. In addition, GIGANTEA (GI)-mediated photoperiodic flowering in $A$. thaliana is coordinately regulated by two different genetic pathways: one mediated by CONSTANS (CO) and the other by miR172 and its targets [26]. MiR399 family members are phosphate-deficient responsive and involved in phosphate homeostasis [29-32]. The miR399s and sucrose are phloem-mobile molecules [31-34], and they may potential interact in the signaling pathway would be particularly interesting. In addition, little is known about the functions of miR399s in photoperiodic response and flowering time determination in maize.

In this study, we aimed to better understand sucrose-responsive miRNAs and the cross-talk that occurs during long photoperiods, miR399s, and sucrose homeostasis in A. thaliana and maize. We screened sucrose-2responsive miRNAs using miRNA array technology in A. thaliana. Small RNA sequencing was also carried out to identify photoperiod-regulated miRNAs in photoperiod-insensitive inbred maize line $\mathrm{H} 4$ and its near-isogenic line NIL, the latter is sensitive to long photoperiods. The miR399s were fully repressed by high sucrose levels at earlier leaf developmental stages. The onset of miR399 expression was extremely sensitive to long photoperiods during the development of maize. In addition, the NIL accumulated a high sucrose level in vivo, which suggested that miR399s participate in photoperiod-regulated networks in maize in response to LD conditions by modulating sucrose accumulation.

\section{Methods}

Plant materials and growth conditions

A. thaliana ecotype Columbia plants were used in this study. A. thaliana seeds were collected in growth chambers (60\% humidity, $100 \mu \mathrm{mol} \mathrm{m}{ }^{-2} \mathrm{~s}^{-1}$ under LED light) in Houghton, Michigan, USA. These seeds were surface sterilized with $70 \%$ ethanol for $1 \mathrm{~min}$ and then soaked in $10 \%$ bleach for $20 \mathrm{~min}$ with agitation every 2 to $3 \mathrm{~min}$. The sterilized seeds were rinsed at least five times with sterilized water and then sown under a hood on agar-solidified Murashige-Skoog (MS) salt medium. The petri-dishes with seeds were maintained at $4{ }^{\circ} \mathrm{C}$ for $72 \mathrm{~h}$ to homogenize germination and break dormancy. Seven days after germination, we transferred the seedlings at similar growth states to culture bottles containing MS medium supplemented with low (1\%) or high $(6 \%)$ level of sucrose or into a phosphate-deficient MS medium with low or high levels of sucrose. All of the seeds were then transferred to a controlled growth chamber set to $22 \pm 1{ }^{\circ} \mathrm{C}$ with a 15 -h light $\left(100 \mu \mathrm{mol} \mathrm{m}{ }^{-2} \mathrm{~s}^{-1}\right) / 9$-h dark photoperiod, which represented LD conditions.

The photoperiod-sensitive NIL, was the cross product of inbred line $\mathrm{H} 4$ and the tropical maize inbred line CML288 described in our previous studies [12]. The latter was acquired from the National Maize and Wheat Improvement Center (CIMMYT), Mexico City, Mexico, while the former, which was the recurrent parent, was a representative of the Chinese inbred line Tangsipingtou. Four plants were grown per pot in $15-\mathrm{cm}$ pots in liquid full-strength Hoagland's medium in the dark in the growth chambers described previously [12].

Seedlings at the four-fully expanded leaf stage were used for the following experiments. Before the sucrose treatment, the seedlings were starved of sucrose by placing them in the dark for $24 \mathrm{~h}$ to completely starve them for sugar [35]. Sets of four-fully expanded leaf stage seedlings were then transferred to full-strength Hoagland's medium containing either $0.25 \mathrm{mM} \mathrm{KH}_{2} \mathrm{PO}_{4}(\mathrm{P}+$, control) or no additional phosphate $\left(\mathrm{P}_{-},\right)$in the dark. One set of the $\mathrm{P}+$ and $\mathrm{P}-$ media contained 3\% sucrose $(\mathrm{S}, \mathrm{LP}+\mathrm{S})$, while another set was without sucrose (LP). Untreated samples $\left(0.25 \mathrm{mM} \mathrm{KH} \mathrm{PO}_{4}\right)$ were maintained as controls and were collected at the same time as the treated samples. Nutrient solutions were renewed daily to ensure $\mathrm{pH}$ stability. Each treatment was repeated for three times. Newly developed leaves from three plants per replicate were collected per $12 \mathrm{~h}$, then frozen immediately in liquid nitrogen, and stored in a $-80{ }^{\circ} \mathrm{C}$ freezer until use. Three biological replicates were performed. 
The maize and Arabidposis seeds used in this study were provided by Dr. Cuiling Wang (Henan University of Science and Technology), and Prof. Hairong Zhang (Henan Agricultural University), respectively.

\section{Starch and sucrose measurements}

$\mathrm{H} 4$ and NIL plant material were selected and collected during four previously defined developmental periods from plants in growth chambers $(2.8 \times 5.6 \times 8.2 \mathrm{~m})$ under LD conditions (15-h light/9-h dark, $25^{\circ} \mathrm{C}, 100 \mu \mathrm{mol} \mathrm{m}^{-2} \mathrm{~s}^{-1}$ light intensity) [12]. We defined four developmental stages according to our previous study [12]. In photoperiod-insensitive inbred line $\mathrm{H} 4$, the vegetative developmental periods corresponded to the period that the SAM always differentiated into leaf primordium (V1: three-fully expanded leaf stage and V2: four-fully leaf stage), whereas reproductive periods that SAM shapes elongated and become a cone (V3: five-fully leaf stage and V4: six-fully leaf stage). In photoperiod-sensitive inbred line NIL, the vegetative developmental periods corresponded to the period that the SAM always differentiated into leaf primordium (V1: three-fully expanded leaf stage and V2: five-fully leaf stage), whereas reproductive periods that SAM shapes elongated and become a cone (V3: six-fully leaf stage and V4: seven-fully leaf stage).

The newly expanded leaves of $\mathrm{H} 4$ and NIL at the four leaf stages were separately ground to fine powders with liquid nitrogen using mortars and pestles. Subsequently, $200 \mathrm{mg}$ of each powdered sample were briefly homogenized with $600 \mu \mathrm{l}$ of distilled water in a microcentrifuge tube and then immediately heated in boiling water for $10 \mathrm{~min}$. After centrifugation at $20,000 \times g$ for $10 \mathrm{~min}$ at $4^{\circ}$ $\mathrm{C}, 100 \mu \mathrm{l}$ of the supernatant was assayed with a spectrophotometer (Hitachi U-2900; Hitachi, Waltham, MA, USA). A commercial assay kit was used to measure the starch content of the insoluble carbohydrate fraction following the manufacturer's instructions (R-Bio-pharm, Darmstadt, Germany). A unique kit was used to determine the sucrose content of the soluble carbohydrate fraction according to the manufacturer's instructions (K-SUFRG Megazyme, Bray, Ireland) as previously described [36]. Newly expanded leaves from five plants each of $\mathrm{H} 4$ and NIL were examined as one biological replicate, and the average values were based on three biological replicates.

\section{Maize RNA extraction, deep sequencing, and data analysis}

For RNA sequencing(RNA-Seq), we collected leaves and SAM tissue from the same plant in growth chambers under LD conditions as described by our previous study [12]. For leaves, equal amounts (mixed from five seedlings) of samples from the mid part of the top fully-expanded leaves were collected at V1, V2, V3, and V4 stages from $\mathrm{H} 4$ and NIL plants, respectively. For SAM, we collected equal amounts stem tips (mixed from five seedlings) described by the morphology observations in our previous study [12]. At each stage, 14 uniform growth seedlings were harvested. The leaf and SAM samples were collected from the same set of five seedlings at each stage for each maize inbred line, respectively. Another nine seedlings (three seedlings per replicate) were combined to analyze gene expression using quantitative reverse transcription PCR (qRT-PCR). Three independent biological replicates were used for the gene expression validation. All of the samples were flash-frozen in liquid nitrogen and then stored at $-80{ }^{\circ} \mathrm{C}$. Total RNA for deep sequencing was isolated using a Plant Total RNA Extraction kit (Bioteke Corporation, Beijing, China) and then treated with DNase I and magnetic oligo(dT) beads following the manufacturer's protocol. cDNA was synthesized using random hexamers and SuperScript II Reverse Transcriptase (Life Technologies, Ontario, Canada). The cDNA libraries were sequenced with 100-bp paired-end reads on the HiSeq 2000 platform (Illumina, Beijing, China) at the Beijing Genomics Institute.

Low-quality reads were removed from the raw data, and the appropriate small RNAs were mapped to miRNAs reported in miRBase (http://www.mirbase.org/). To compare relative expression levels, sequence counts were normalized in terms of reads per million (RPM).

After normalization, miRNA sequences present at levels $<1$ RPM in the four samples were discarded [37]. For the identification of novel miRNAs, the Mireap software program was used to analyze unannotated small RNA reads. Small RNAs fulfilling the strict criteria described by Ding et al. [38] were deemed to be novel miRNAs. Only those candidates with a minimal folding free energy index $>0.85$ were treated as novel maize miRNAs [38].

The differential expression of miRNAs between two inbred lines was analysed by DESeq [39]. MiRNAs were considered up- or down-regulated on the basis of two criteria: a $\mid \log 2$ fold change $\mid>1$ and a false discovery $<$ 0.05 , and $P$-value could be assigned to each miRNA and adjusted by the Benjamini and Hochberg's approach for controlling the false discovery rate.

\section{Computational predictions and functional analyses of maize miRNA targets}

The potential targets of miRNAs in maize were predicted using psRNATarget software with default parameters [40]. The target searching was performed using the maize PlantGDB genomic CD library. Potential miRNA targets were functionally annotated by comparing them with the gene ontology (GO) database using AgriGO (http://bioinfo.cau.edu.cn/agriGO/) with default parameters.

\section{qRT-PCR validation in maize}

To validate the miRNA expression levels identified by RNA-Seq, we performed the qRT-PCR analysis of all 
differentially expressed miRNAs in this study. Total RNAs from the fully expanded leaves and SAM of six $\mathrm{H} 4$ and NIL plants harvested at each of the V1, V2, V3, and V4 stages were extracted using RNAiso Plus (Takara, Dalian, China). Three biological replicates were performed. cDNA was synthesized using a miRNA cDNA synthesis kit (Takara) following the manufacturer's protocol. The reverse transcription of small RNAs was carried out using a SYBR Prime Script miRNA RT-PCR kit (Takara) according to the manufacturer's instructions. Validation of miRNAs by qRT-PCR was performed on a CFX9 Real-Time System (Bio-Rad, Hercules, CA, USA) using SYBR Premix Ex Taq II (Takara) and Roche FastStart Universal SYBR Green Master (Rox) mix (Roche, Basel, Switzerland), respectively. The $2^{-\Delta \Delta C t}$ relative quantification method was used to analyze relative gene expression levels, using the 5S RNA (miRNA qRT-PCR) and 18S RNA (target gene qRT-PCR) genes used as standards. To verify the sequencing results, 10 conserved and 5 novel miRNAs were selected for amplification. Primer specificity was verified by a melting curve analysis. The reverse primer used for qRT-PCR amplification of miRNAs was the Uni-miR qRT-PCR primer in the miRNA cDNA synthesis kit. The remaining qRT-PCR primers are listed in the Additional file 1. Three biological replicates in technical triplicate were performed for all samples. Data were statistically analyzed using ANOVA, and means were compared using Duncan's multiple range test at $P<0.05$ level in SPSS V. 20.0.

\section{A. thaliana RNA isolation and northern blot analysis}

Total leaves RNAs from $A$. thaliana grown in MS salt medium supplemented with $1 \%$ or $6 \%$ sucrose for 3 weeks and then in a phosphate-free medium for 2 weeks were isolated using Trizol reagent (Takara). The protocol for the northern blot analysis was previously described [41]. Briefly, a 20- $\mu$ g aliquot of each RNA sample was mixed with RNA sample buffer and then separated on a $15 \%(w /$ v) urea-PAGE denatured gel. The separated RNAs were electro-transferred to Hybond-N membranes (Amersham Biosciences, Beijing, China), which were then rinsed with $2 \times$ SSPE buffer to remove gel fragments. RNAs were further fixed to membranes by UV cross-linking. After pre-hybridization for $2 \mathrm{~h}$ in hybridization buffer at $37{ }^{\circ} \mathrm{C}$, hybridization was performed in hybridization buffer containing DNA oligonucleotides labelled with $\left[\gamma-\mathrm{P}^{32}\right]$ ATP overnight at $37^{\circ} \mathrm{C}$. After hybridization, membranes were washed with $2 \times \mathrm{SSC} / 0.1 \%(\mathrm{w} / \mathrm{v}) \mathrm{SDS}$ at $37^{\circ} \mathrm{C}$ for $30 \mathrm{~min}$; this process was repeated three times. Autoradiography was carried out by maintaining blotted membranes overnight on phosphorimager screens, followed by scanning with a Typhoon scanner. ImageQuant software was used for quantification of the radio signals.

\section{Results}

Growth traits and sucrose contents in photoperiodsensitive and photoperiod-insensitive maize inbred lines under LD conditions

Under LD conditions, NIL plants were considerably taller than those of the H4 line (Fig. 1a). H4 plants showed less photoperiodic sensitivity than NIL plants, which exhibited a one-week delay in flowering under LD conditions (Fig. 1a and b). To examine changes in the sucrose contents of maize seedlings in response to photoperiod, individual samples of $\mathrm{H} 4$ and $\mathrm{NIL}$, were periodically collected and the plant phenotypes were observed at V1, V2, V3, and V4 stages under LD conditions. At the V2 stage under LD conditions, the NIL accumulated significantly greater biomass and sucrose content than $\mathrm{H} 4$, whereas relatively steady levels of starch and glucose were identified during these stages (Fig. 1c and d). Thus, a long photoperiod had an important influence on flowering time and the accumulation of sucrose in vivo.

\section{Identification of miRNA expression patterns in leaves and SAM under LD conditions during the four studied maize leaf stages}

To investigate potential differences in miRNA expression patterns during photoperiod-dependent floral transitions between $\mathrm{H} 4$ and NIL plants under LD conditions, we performed small RNA-Seq using SAM tissues and leaves from the V1 to V4 stages of these two genotypes grown under LD conditions. This sequencing generated 13 to 23 million reads from each $\mathrm{H} 4$ or NIL sample. After removing adapters and low-quality reads, the remaining clean reads, representing $96 \%$ of the total reads, were retained for further analysis (Table 1). As shown in Table 1, more than $55 \%$ of these reads could be matched perfectly to the maize genome. Analysis of small-RNA length distributions (Fig. 2a and b) in the four maize samples indicated a peak size of $21 \mathrm{nt}$ from leaves and $24 \mathrm{nt}$ from SAM, which suggested the organ-specific accumulation of miRNAs.

miRDeep2 was used to identify known miRNAs based on clean reads obtained from the RNA-Seq. In total, 197 known miRNAs belonging to 27 different families were identified in the two inbred lines (Additional file 2). The two largest conserved families were miR166 and miR399, with 22 and 18 members, respectively (Additional file 2). Twelve novel miRNA candidates were co-detected in leaves and SAM from the two inbred lines, and $24 \mathrm{miR}$ NAs were specifically predicted in leaves, while 13 were identified in SAM (Fig. 2c). However, most of the novel predicted miRNAs were expressed at relatively low levels and were exclusively detected in one or two libraries.

Prediction of miRNA targets in maize leaves and SAM

To predict targets of both conserved and novel predicted miRNAs obtained from RNA-Seq, we used 

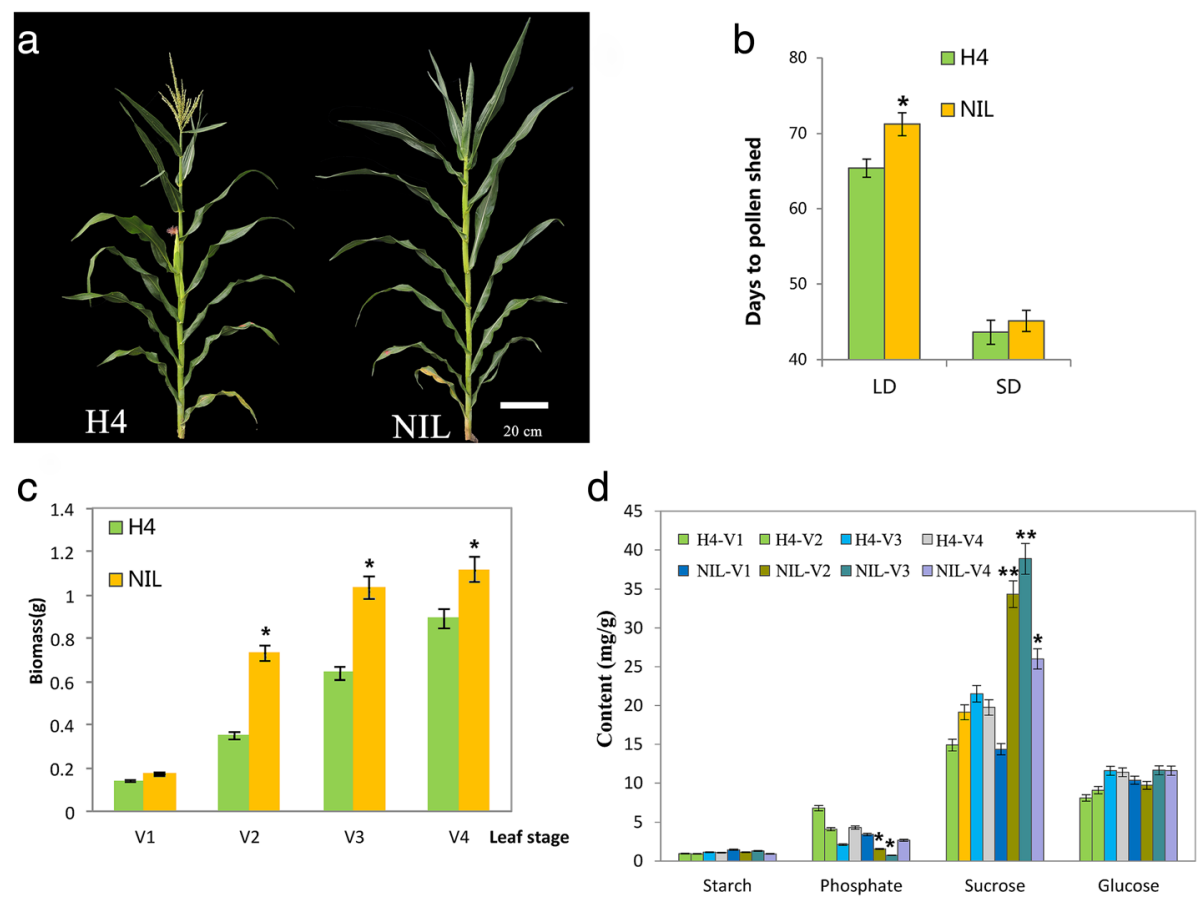

Fig. 1 Phenotypes and growth parameters of maize lines $\mathrm{H} 4$ and NIL. a Plant morphology of maize inbred line H4 and its near isogenic line NIL under long-day conditions. b Days to pollen shed under long-day (Zhengzhou, Henan) and short-day (Sanya, Hainan) conditions. c Biomasses of maize seedlings of the inbred $\mathrm{H} 4$ and NIL at different developmental stages (means \pm SEs, $n=6$ ). $\mathbf{d}$ Starch and sucrose contents of $\mathrm{H} 4$ and NIL seedlings. Significant differences between $\mathrm{H} 4$ and NIL were assessed using Student's t-test; ${ }^{*} P<0.05,{ }^{* *} P<0.01$

Table 1 Summary of the miRNA sequencing of individual libraries

\begin{tabular}{|c|c|c|c|c|}
\hline & total reads & clean reads & unique reads & perfectly mapped to genome \\
\hline LH4-V1 & $17,186,960$ & $16,963,404(98.69 \%)$ & $2,052,631(12.10 \%)$ & $1,197,905(58.35 \%)$ \\
\hline LH4-V2 & $13,380,625$ & $13,243,556(98.97 \%)$ & $2,087,027(15.75 \%)$ & $1,233,404(59.09 \%)$ \\
\hline LH4-V3 & $17,751,014$ & $17,568,846(98.97 \%)$ & $2,374,513(13.51 \%)$ & $1,358,280(57.20 \%)$ \\
\hline LH4-V4 & $19,505,369$ & 19,300,302(98.94\%) & $2,116,078(10.96 \%)$ & $1,221,134(57.70 \%)$ \\
\hline LNIL-V1 & $10,007,901$ & $9,881,920(98.74 \%)$ & $1,665,835(16.85 \%)$ & $961,709(57.73 \%)$ \\
\hline LNIL-V2 & $17,805,863$ & $17,645,763(99.10 \%)$ & $2,697,086(15.28 \%)$ & $1,551,514(57.52 \%)$ \\
\hline LNIL-V3 & $22,374,571$ & $21,819,878(97.52 \%)$ & $1,811,746(8.30 \%)$ & $1,057,255(58.35 \%)$ \\
\hline LNIL-V4 & $21,309,723$ & $21,052,171(98.79 \%)$ & $3,222,375(15.3 \%)$ & $1,793,192(55.64 \%)$ \\
\hline SH4-V1 & $22,807,477$ & $22,338,639(98.45 \%)$ & $6,313,116(28.26 \%)$ & $3,650,905(57.83 \%)$ \\
\hline SH4-V2 & $18,426,335$ & $18,224,946(99.47 \%)$ & $5,301,591(29.08 \%)$ & $3,075,100(58.00 \%)$ \\
\hline $\mathrm{SH} 4-\mathrm{V} 3$ & $20,899,478$ & 20,677,910(99.53\%) & $6,382,101(30.86 \%)$ & $3,724,696(58.36 \%)$ \\
\hline SH4-V4 & $23,288,648$ & $23,026,184(99.45 \%)$ & $7,010,719(30.44 \%)$ & $4,070,374(58.05 \%)$ \\
\hline SNIL-V1 & $21,959,560$ & $21,639,576(99.07 \%)$ & $6,242,915(28.84 \%)$ & $3,617,275(57.94 \%)$ \\
\hline SNIL-V2 & $19,457,112$ & $19,218,834(99.35 \%)$ & $6,461,810(33.62 \%)$ & $3,737,160(57.83 \%)$ \\
\hline SNIL-V3 & $19,713,918$ & $19,465,370(99.27 \%)$ & $5,947,829(30.55 \%)$ & $3,418,295(57.47 \%)$ \\
\hline SNIL-V4 & $19,396,171$ & $18,651,525(96.69 \%)$ & $5,076,368(27.21 \%)$ & $2,957,408(58.25 \%)$ \\
\hline
\end{tabular}




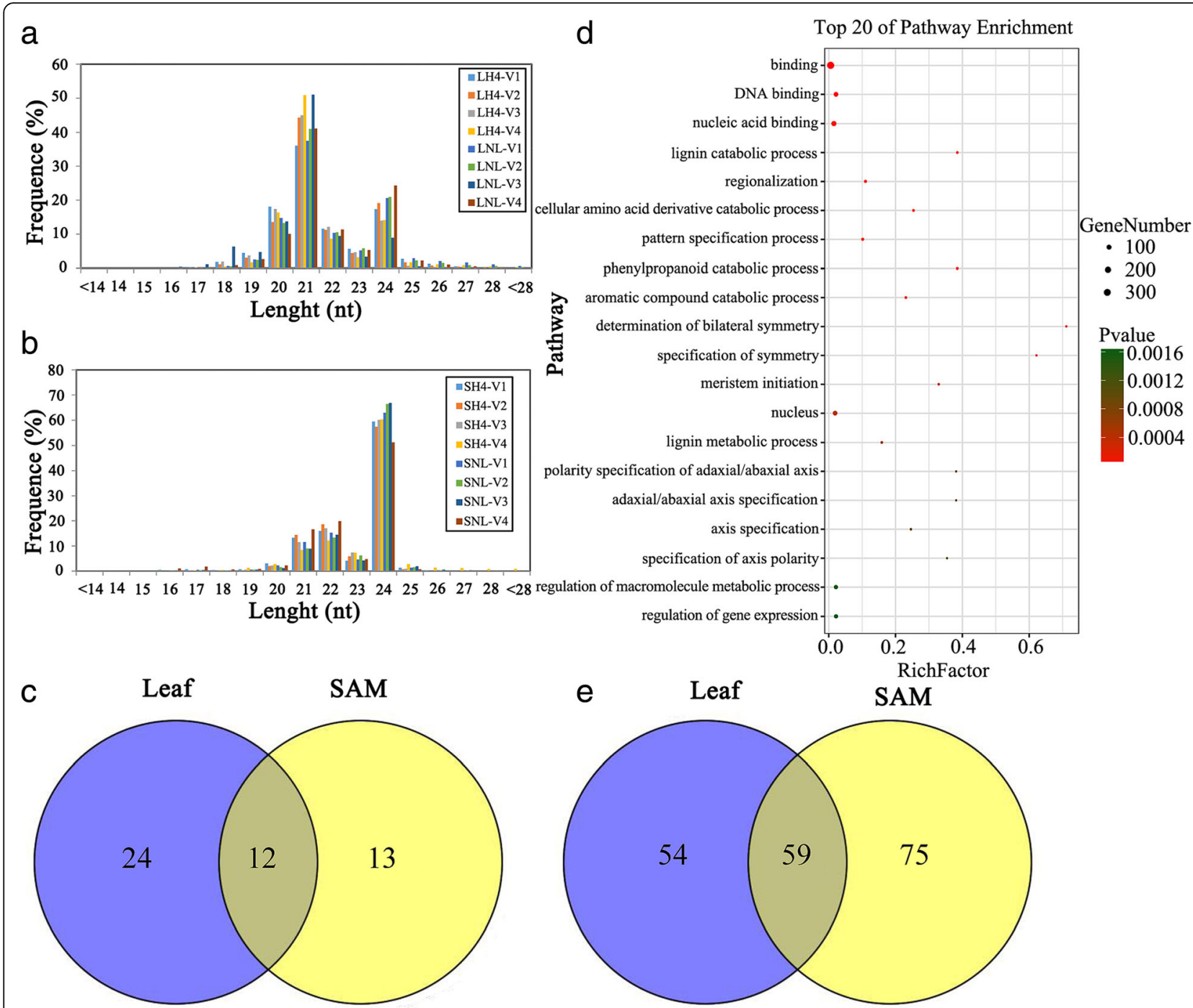

Fig. 2 Characteristics of small RNA libraries from leaves and SAM of maize $\mathrm{H} 4$ and NIL obtained by miRNA sequencing. a-b Comparison of size distributions of small RNA libraries in leaves (a) and SAM (b) of H4 and NIL. (c) Venn diagram of novel miRNAs in leaves and SAM of H4 and NIL (d) Top 20 of GO functions significantly enriched with target genes of both conserved and novel predicted miRNAs obtained from RNA sequencing. e Venn diagram of differentially expressed conserved miRNAs in leaves and SAM between H4 and NIL

psRNATarget, which revealed 1009 targets of 291 known miRNAs and 86 targets of 12 novel miRNAs (Additional file 3). Potential functional annotations of the miRNA targets were performed using GO analyses [42]. The 1095 target genes were assigned to 73 significant GO terms $(P<0.05)$ (Fig. $2 d$; Additional file 4). Binding (GO: 005488) was a dominant term in the category of molecular function, corresponding to $77.1 \%$ of 428 genes. Regionalization (GO: 0003002) was enriched in the biological process category (Fig. 2d). Floral-related functions of target genes were further identified, such as floral organ development (GO: 0048437), floral whorl development (GO: 0048438), and flower development (GO: 0009908) (Additional file 4).
MiRNAs expression patterns in response to LD conditions in maize leaves and SAM

As revealed by the deep sequencing results, the expression levels of almost all miRNAs changed during the progression of maize development from the V1 to V4 stages. Totally, 113 and 134 known miRNAs displayed significantly different expression levels in maize leaves and SAM, respectively (Fig. 2e). As shown in Additional file 5, in contrast to other LD-induced miRNAs, miR399d and miR399j were strongly induced in $\mathrm{H} 4$ leaves by LD conditions, with a greater than 10-fold expression difference at the V2 and V3 stage. The expressions of miR399d, and miR399i were LD-induced in SAM but significantly down-regulated in NIL (Additional file 5). This result indicated that 
miR399 plays an important role in the LD photoperiodic regulation of both the NIL's leaves and SAMs.

To validate the miRNAs identified by RNA-Seq in maize leaves and SAM, 5 novel maize miRNAs (miRn018, miRn023, miRn024, miRn027, and miRn032) and 10 conserved miRNA families (miR156, miR159, miR167, miR169 miR172, miR390, miR393, miR398, miR399 and miR827) were subjected to qRT-PCR analyses. Relative expressions of selected miRNAs in H4 and NIL during the four studied developmental stages as assessed by qRT-PCR were consistent with those from the deep-sequencing data, with a relative $R^{2}$ value of 0.733 (Fig. 3).

\section{The effect of external sucrose on miR399 expression in maize}

The sharp expressional changes of miR399s during the transition from vegetative to reproductive phases indicated that this miRNA family is associated with flowering time under LD conditions in maize. In addition, more sucrose accumulated in the NIL than in $\mathrm{H} 4$ in response to LD condition. To explore the relationships between miR399s and sucrose accumulation in maize, H4 and NIL seedlings were subjected to high sucrose and phosphate deficiency. MiR399a and miR399d showed significantly elevated expression levels in both H4 and NIL under LD plus phosphate starvation conditions; however, the inbred lines grown under phosphate deficiency and in the presence of sucrose $(\mathrm{P}-\mathrm{S}+)$ had relatively lower miR399 expressions levels than those grown in the absence of both compounds (P- S-). In addition, seedlings subjected to high sucrose exhibited lower miR399 expression levels compared with those grown under other treatment conditions (Fig. 4). In contrast, the target genes of the miR399s displayed opposite expression patterns compared with those of the miR399s under these treatment conditions. Thus, external sucrose supplementation may inhibit miR399 expression in maize. The expression of miR399 was lower in the NIL than in H4, which further supported our previous conclusions based on RNA-Seq results from these two inbred lines.

\section{Temporal expression of phosphate homeostasis-related genes under long-day conditions in maize}

The miR399 family is involved in phosphate uptake in various plant species [30, 43, 44]. Our results mentioned above suggest that the expression of miR399s family's expression level was affected by external sucrose. In addition, we observed that phosphate homeostasis-related genes were differentially expressed between $\mathrm{H} 4$ and NIL (Fig. 5). In contrast to the expression levels of miR399s, PHO2 (GRMZM2G464572 and GRMZM2G 381709), a miR399 target gene, was more highly expressed in leaves at V2, V3, and V4 stages, while elevated expression was also observed in SAM at V2 and V3 stages in NIL (Fig. 5a-c). Thus, miR399s may regulate $\mathrm{PHO} 2$ at least partially by cleaving this gene during $\mathrm{V} 2$ and V3 stages in response to LD conditions. One of six phosphate transporter (PHT) genes, PHT4;1, was

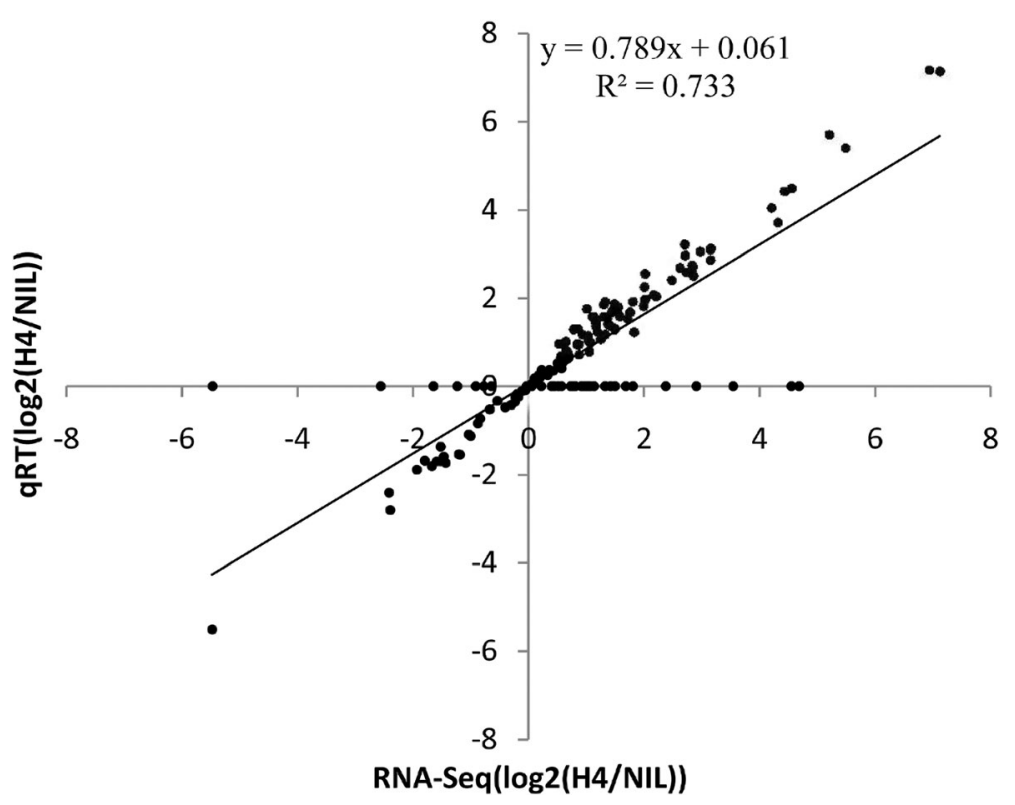

Fig. 3 Validation of differentially expressed miRNAs inferred from RNA sequencing data between the maize H4 and NIL using quantitative realtime PCR. Seventeen miRNAs exhibiting diverse expression profiles in the RNA-seq data were selected for qPCR analysis. The average value of each gene based on RNA-seq expression data was plotted against that from qPCR result and fit into a linear regression. Both $x$ - and $y$-axes are indicated by $\log 2$ scales 


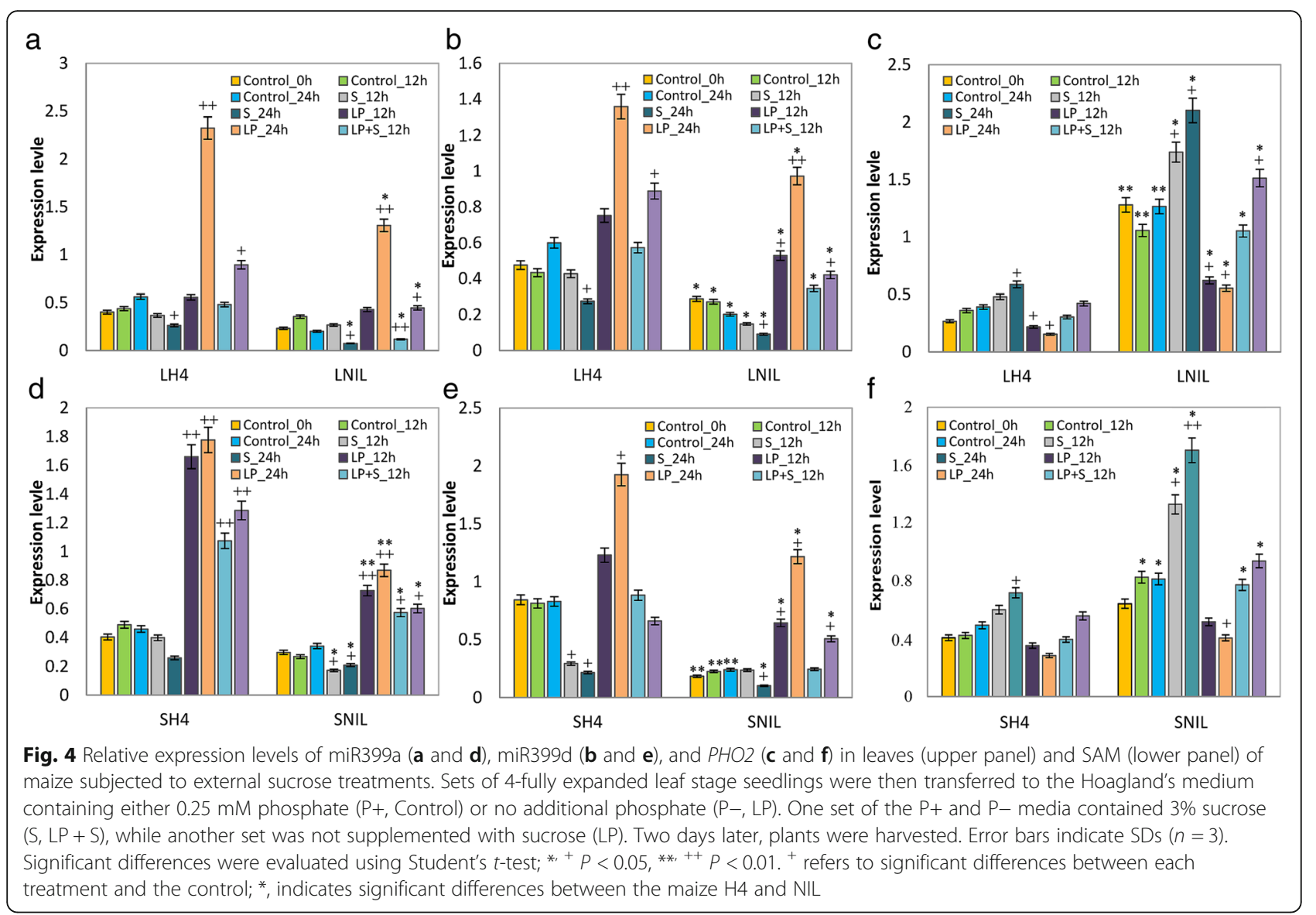

differentially expressed between $\mathrm{H} 4$ and NIL in leaves and SAM during V2 and V3 stages (Fig. 5d-i). These data imply that miR399-mediated regulation of target genes and essential phosphate transporters during V2 and V3 stages may be affected by LD conditions.

\section{Inhibition of miR399 expression by external sucrose in $A$. thaliana}

To validate the expression of the miR399s family under $\mathrm{S}_{+}$ condition, qRT-PCR was carried out in A. thaliana subjected to a supplement of $6 \%$ sucrose. Plants grown under the same conditions without any additional sucrose served as controls. As shown in Fig. 6a and b, miRNA399 expression levels were approximately twofold lower in the $6 \%$ sucrose-supplemented plants than in S- plants at the 5-week stage (Fig. 6c and d). In addition, the expressions of miRNA399s as revealed by northern blotting, were in plants subjected to phosphate starvation in $\mathrm{S}_{+}$compared with S-, (Fig. 6e). These results indicated that $\mathrm{S}+$ inhibited miR399 expression during the latter stages of $A$. thaliana development. In addition, $A$. thaliana plants grown with $6 \%$ sucrose $(\mathrm{S}+, \mathrm{P}+)$ exhibited later flowering than plants treated with $1 \%$ sucrose $\left(\mathrm{S}_{-}, \mathrm{P}_{+}\right.$, the normal growth concentration; Additional file 6). Three weeks after germination, $75 \%$ of $(\mathrm{S}-, \mathrm{P}+)$-treated plants were flowering, whereas only $16 \%$ of $\left(\mathrm{S}_{+}, \mathrm{P}+\right)$ treated plants were flowering or close to flowering (Additional file 6). This result indicated that external sucrose supplements can inhibit the miR399 expression and delays flowering in A. thaliana.

\section{Discussion}

Relationships among miR399s, photosynthesis, and sugars/sucrose in plants

An association between miR399s and photosynthesis has been frequently reported, which indicates that photosynthesis and sugars are related to the P signaling pathway. Stem girdling, a method commonly used to block the transfer of sugar or photosynthates to roots, induces the accumulation of PSI gene transcripts in white lupin (Lupinus albus). A similar phenomenon has also been observed in response to sucrose, which implies that sugar, sucrose, and photosynthesis play critical roles in plant response to $P$ deficiency [45]. In addition, microarray expression analyses have revealed that the pho3 mutant exhibits low expression level of the SUC2 gene, which encodes a sucrose transporter [46, 47]. This result suggests that sugar sensing is tightly related to Pi starvation.

Several regulatory miRNAs have been implicated in maintaining the homeostasis of nutrients, such as phosphate, copper, and salt [48-50]. The miR399 family can 


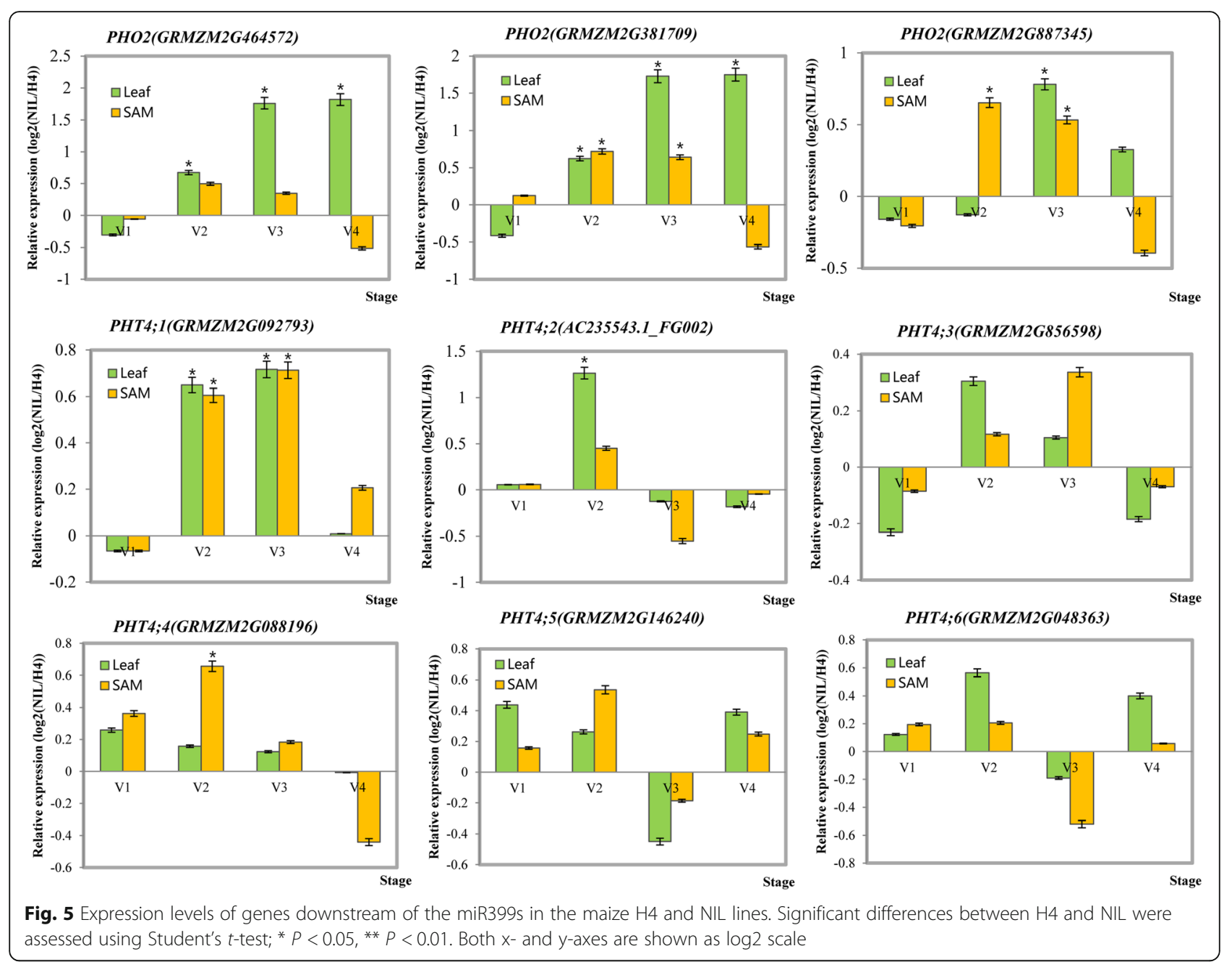

be translocated between root and shoots, and $\mathrm{P}$ responses in roots may be determined by miR399 translocation in phloem and P levels in shoots [31, 32, 51]. Significantly, sucrose loading and unloading also indirectly influence miR399 responses and P accumulation because of their similar translocation in the phloem [52]. In our study, sucrose accumulated at greater levels in the NIL at the V2 and V3 stages, whereas miR399 expression was lower (Fig. 1d and Additional file 5), thus suggesting a predicted negative correlation between miR399s and internal sucrose in maize.

\section{Flowering-responsive miRNAs in maize}

Changes in photoperiod affect maize output by controlling the phase transition from vegetative to reproductive growth, but photoperiod-regulated miRNAs have not yet been identified in this species under LD condition. In this study, small-RNA-Seq was carried out using leaves and SAM from photoperiod-sensitive and insensitive maize inbred lines grown under LD conditions.

Numerous miRNAs, such as miR156, miR159, miR172, and miR169, displayed different expression levels between these two genotypes (Additional file 5). The regulation of these miRNAs during flowering time has been reported in many species, but only miR156 and miR172 are the only conserved miRNAs regulated by LD photoperiod [53-59]. MiR156 and miR172 target genes encode SPL transcription factors and AP2-like family genes, respectively. Together with their targets, these two miRNAs form a network that regulates flowering by controlling downstream genes such as AP1, LFY, FUL, and FT [26, 44, 59-62]. These flowering-related genes are also regulated by other miRNAs that are involved in controlling flowering time [53, 57]. In addition, flowering-regulated miRNAs are also controlled by other factors, such as abiotic stress, and hormones including gibberellin and auxin (Fig. 7a). 


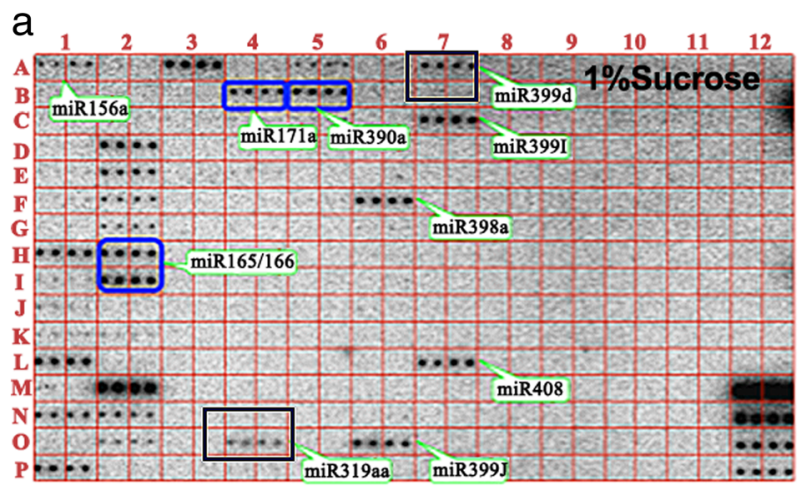

b
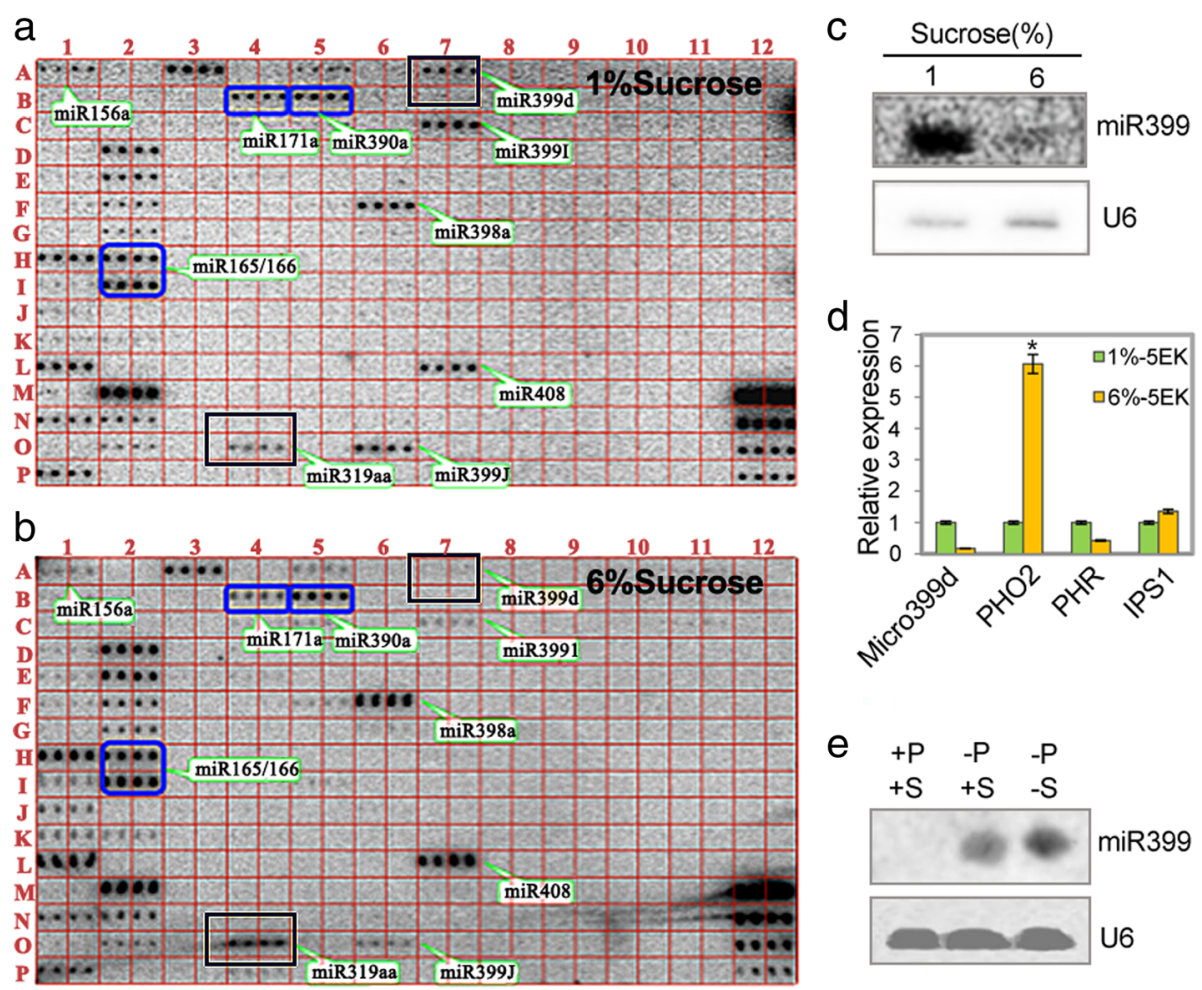

Fig. 6 Identification of sucrose-regulated miRNAs from A. thaliana subjected to external sucrose supplementation. a-b Identification of sucroserelated miRNAs by miRNA array analysis. Total RNAs $(100 \mu \mathrm{g})$ isolated from 5-week old A. thaliana wild-type plants grown on MS medium supplemented with 1\% (a) and 6\% (b) sucrose were used for miRNA detection on a 15\% PAGE gel. (c) Northern blot validation of miR399s in A. thaliana. $\mathbf{d}$ Expression levels of phosphate-responsive genes in 5-week old A. thaliana plants subjected to external sucrose supplementation as assessed by northern blotting. e Relative expression levels of miR399s in response to external sucrose supplementation under phosphate starvation conditions

\section{MicroRNA 399 as a potential integrator of photo- response, phosphate homeostasis, and sucrose signaling under LD condition}

According to Fuji et al. (2005) [48], miR399s are associated with phosphate starvation responses in $A$. thaliana. This miRNA family has been found to be significantly induced under $\mathrm{P}$ deficiency, and its target gene AtUBC24/PHO2 has been verified to encode ubiquitin E2-conjugating enzyme [29]. In addition to their involvement in the maintenance of phosphate homeostasis, miR399 and its target gene $\mathrm{PHO} 2$ regulate temperature-responsive flowering in $A$. thaliana [63]. PHO2 loss of function and miR399b overexpression both cause early flowering by increasing TWIN SISTER OF FT expression under LD conditions. In addition, miR399-mediated PHO2 cleavage may regulate photoperiodic flowering independent of $C O$ [63]. In our study, the $\mathrm{PHO} 2$ expression was significantly increased during the vegetative to reproductive transition (Fig. 5), which was the opposite trend to that of miR399 expression. In addition, NIL plants exhibited delayed flowering accompanied by the decreased expression of miR399s and high internal sucrose levels.
This suggested that high sucrose level might regulate flowering time in part by inhibiting miR399 expression, thereby leading to later flowering (Fig. 7b). Nevertheless, whether the target gene $\mathrm{PHO} 2$ precisely regulates the expression of the downstream floral genes (such as FT) during sucrose responses in maize is still unknown.

Together, miR399 should play an important role in phosphate signaling and the flowering response pathway. In addition, only one gene encoding phosphate transporters was differentially expressed between $\mathrm{H} 4$ and NIL, PHT4;1. This gene's expression level was most significantly differences during the V2 and V3 stages (Fig. 5). In an earlier study, recombinant CCA1 protein controlled the circadian expression of PHT4;1 by binding to the gene's promoter region, which suggested that the CCA1 protein directly regulates the PHT4; 1 gene at the transcriptional level [64]. Normal circadian control of the degradation rate of starch by CCA1/LHY has also been reported and this regulation is essential for preventing growth penalties and sucrose starvation at night [65-67]. According to our qRT-PCR analysis, the $\mathrm{ZmCCA}$ expression level was elevated in NIL, a maize 


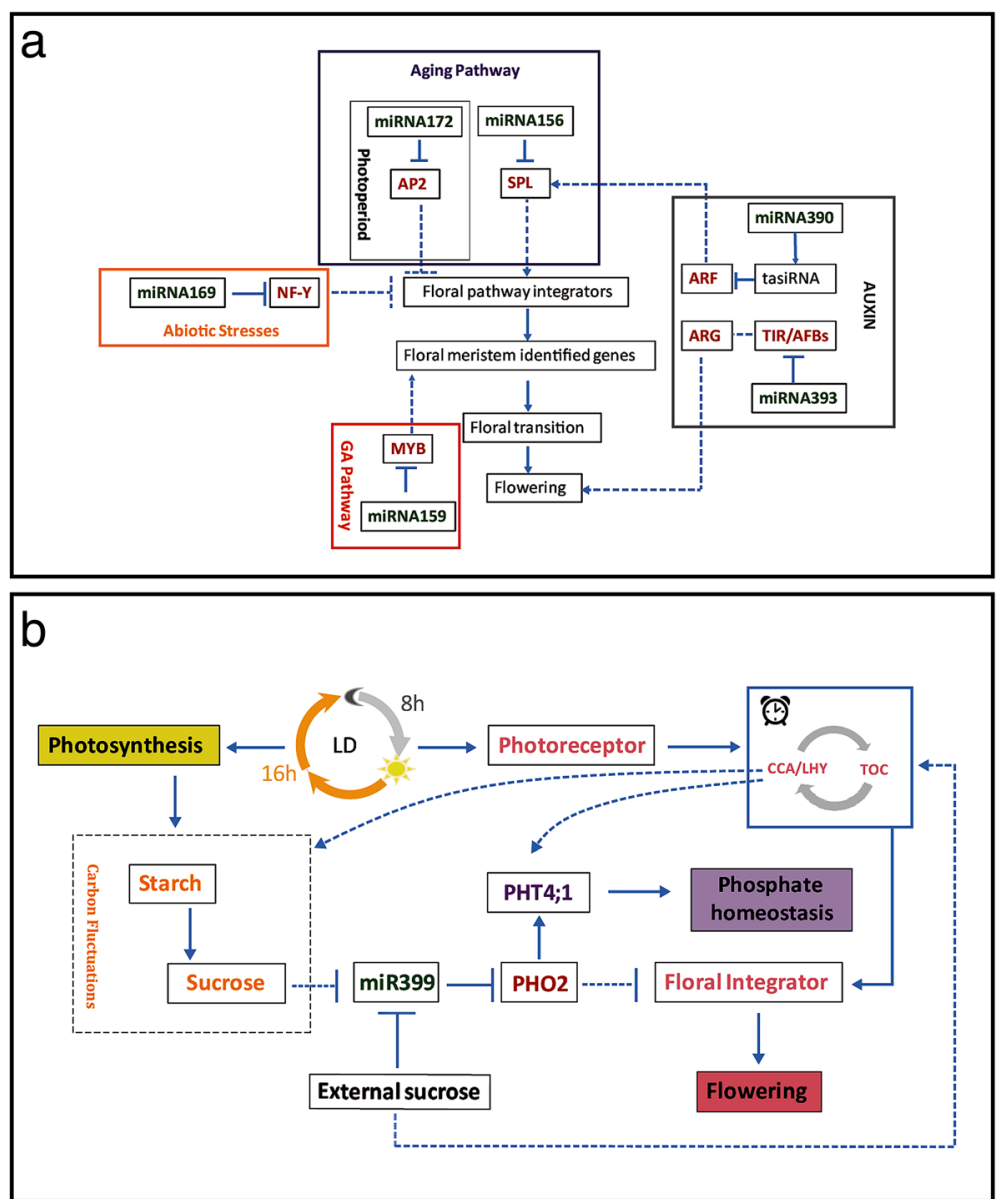

Fig. 7 A proposed schematic model of mechanisms involving miRNAs and their target genes under long-day conditions and external stress. a Several miRNAs with different expression patterns may be indirectly involved in the plant floral transition by regulating target gene expression levels. The miR156 family, is the main regulator of 11 of the 17 SPL transcription factors. Rising SPL levels positively regulate miR172 expression, resulting in the suppression of the AP2-type floral repressors. The miR159 families regulate MYB transcription factors, respectively and the expression levels rise in response to increased GA signaling. The miR390 family regulates flowering indirectly by promoting the production of tasiRNAs from the TAS3 locus, which negatively regulates the ARF3/4 transcription factors. Additionally, miR393 regulates flowering through controlling over the expression of auxin-responsive genes. The stress-induced miR169-NF-Y module regulates flowering time by inhibiting the floral integrators genes, respectively. $\mathbf{b}$ Possible regulatory mechanism involving the circadian clock, phosphate homeostasis, and sugar metabolism in plant mediated by miR399-PHO model. Dotted line represents weak interaction in comparison with a solid arrow. Arrows represent activation; line with a bar represents repression. MiRNAs are shown in bold green font and their respective targets are shown in red. Abbreviations: AP2, APETALA 2-TYPE PROTEIN; SPL, SQUAMOSA PROMOTER-BINDING PROTEIN-LIKE; NF-Y, NUCLEAR FACTOR Y; TIR1, TRANSPORT INHIBITOR RESPONSE 1; AFB1 (AUXIN SIGNALING F BOX PROTEIN 1); ARGs, auxin-responsive genes; ARF, AUXIN RESPONSE FACTOR; LD, long day; PHO2, PHOSPHATE 2; GI, GIGANTEA; TOC1, TIMING OF CAB EXPRESSION 1; CCA1, CIRCADIAN CLOCK-ASSOCIATED 1; LHY, LATE ELONGATED HYPOCOTYL(LHY)

line that accumulated more sucrose than H4 (Fig. 1d and Additional file 7); in contrast, the expressions of miR399s were lower in NIL at the development transition stage. We concluded that ZmCCA-mediated sucrose accumulation may inhibit miR399 expression, but promote the expression of the target gene $\mathrm{PHO} 2$ and phosphate transporter genes to regulate phosphate homeostasis (Figs. 4 and 5). However, further experimental evidence is needed to precisely define the roles of $Z m C C A s, m i R 399 s$, and sucrose in the maize LD-photoperiodic pathway (Additional file 7).

\section{Conclusions}

In this study, we used the photoperiod-sensitive NIL, which has a higher sucrose accumulation and a delayed flowering phenotype compared with the photoperiod-insensitive line $\mathrm{H} 4$, to explore the relationships among $\mathrm{LD}$ conditions, miR399s, and sucrose. External sucrose supplementation in maize and A. thaliana demonstrated that high external sucrose can inhibit the expression of miR399s. In addition, the higher sucrose accumulation in the NIL observed in vivo, accompanied by the higher miR399 expression may provide new insights on the 
integration of sucrose and miR399 family levels with flowering time regulation under LD conditions. Finally, our findings help establish a novel link between LD-photoperiod and carbon metabolism in plants.

\section{Additional files}

Additional file 1: Primers used in the quantitative real-time RT-PCR analysis. (XLSX $10 \mathrm{~kb}$ )

Additional file 2: MiRNA families identified in the leaves and SAM of the maize $\mathrm{H} 4$ and NIL inbred lines. (XLSX $12 \mathrm{~kb}$ )

Additional file 3: Predicted targets of known and novel miRNAs. (XLSX $372 \mathrm{~kb}$ )

Additional file 4: Functional enrichment analyses of miRNA targets based on gene ontology (GO). (XLSX $27 \mathrm{~kb}$ )

Additional file 5: Differentially expressed miRNAs in leaves and SAM between $\mathrm{H} 4$ and NIL. (XLSX $106 \mathrm{~kb}$ )

Additional file 6: Phenotypes of $A$. thaliana grown MS medium supplemented with high sucrose at different developmental phases. (a) Phenotypes of 2-week-old plants under high sucrose conditions. (b) Percentages of flowering plants at different developmental phases. (TIF $805 \mathrm{~kb}$ )

Additional file 7: Expression levels of CCA genes in the maize $\mathrm{H} 4$ and NIL lines. (TIF 167 kb)

\section{Abbreviations}

CO: Constans; FT: Flowering locus t; Gl: Gigantea; GO: Gene ontology; LD: Long day; miRNA: MicroRNA; qRT-PCR: Quantitative real-time PCR; SAM: Shoot apical meristem; SOC1: Supressor of overexpression of constans1; SPL: Squamosa promoter binding protein-like; ZCN1: Zea mays CENTRORADIALIS1

\section{Acknowledgments}

The authors would like to thank James Schnable for providing technical assistance with the small RNA-seq data, and many undergraduate students for their expert care of our plants and important contributions.

\section{Funding}

This study was financially supported by grants from the National Key Research and Development Program of China (2016YFD0101001), and the National Natural Science Foundation of China (31371628).

\section{Availability of data and materials}

All raw sequence reads have been deposited in the NCBI Sequence Read Archive (http://www.ncbi.nlm.nih.gov/sra) under SRA accession numbers SRP118408.

\section{Authors' contributions}

YHC and GLT designed the experiments and performed the analyses. LT, HPL and LGR analyzed the results and wrote the manuscript. LT, LXK, LJW, MNL, SXW, JLZ and XHS conducted all of the experiments. HPL, LGR, JZ, DDD and HFL contributed to the data analyses and manuscript revisions. All authors have read and approved the final version of the manuscript.

\section{Ethics approval and consent to participate} Not applicable.

\section{Consent for publication}

Not applicable.

\section{Competing interests}

The authors declare that they have no competing interests.

\section{Publisher's note}

Springer Nature remains neutral with regard to jurisdictional claims in published maps and institutional affiliations.

\section{Author details}

'College of Agronomy, National Key Laboratory of Wheat and Maize Crop

Science, Henan Agricultural University, Zhengzhou 450002, China.

${ }^{2}$ Department of Biological Sciences, Michigan Technological University, Houghton, MI 49931, USA. ${ }^{3}$ College of Life Science, Northwest Agriculture and Forestry University, Yangling 712100, China. ${ }^{4}$ Cereal Institute, Henan Academy of Agricultural Science/Henan Provincial Key Laboratory of Maize Biology, Zhengzhou 450002, China.

Received: 13 June 2018 Accepted: 3 October 2018

Published online: 21 November 2018

\section{References}

1. Buckler ES, Holland JB, Bradbury PJ, Ahcarya CB, Brown PJ, Browne C, et al. The genetic architecture of maize flowering time. Science. 2009:325:714-8.

2. Tian F, Stevens NM, Buckler ES. Tracking footprints of maize domestication and evidence for a massive selective sweep on chromosome 10. Proc Natl Acad Sci U S A. 2009;106:9979-86.

3. Kumimoto RW, Zhang Y, Siefers N, Holt BF 3rd. NF-YC3, NF-YC4 and NF-YC9 are required for CONSTANS-mediated, photoperiod-dependent flowering in Arabidopsis thaliana. Plant J. 2010;63:379-91.

4. Knuesting J, Riondet C, Maria C, Kruse I, Becuwe N, Konig N, et al. Arabidopsis glutaredoxin S17 and its partner, the nuclear factor $\mathrm{Y}$ subunit C11/negative cofactor Zalpha, contribute to maintenance of the shoot apical meristem under long-day photoperiod. Plant Physiol. 2015;167:1643-58.

5. Noh YS, Bizzell CM, Noh B, Schomburg FM, Amasino RM. EARLY FLOWERING 5 acts as a floral repressor in Arabidopsis. Plant J. 2004;38:664-72.

6. Putterill J, Laurie R, Macknight R. It's time to flower: the genetic control of flowering time. BioEssays. 2004;26:363-73.

7. Danilevskaya ON, Meng X, Hou Z, Ananiev EV, Simmons CR. A genomic and expression compendium of the expanded PEBP gene family from maize. Plant Physiol. 2008;146:250-64.

8. Miller TA, Muslin EH, Dorweiler JE. A maize CONSTANS-like gene, conz1, exhibits distinct diurnal expression patterns in varied photoperiods. Planta. 2008:227:1377-88.

9. Lazakis CM, Coneva V, Colasanti J. ZCN8 encodes a potential orthologue of Arabidopsis $\mathrm{FT}$ florigen that integrates both endogenous and photoperiod flowering signals in maize. J Exp Bot. 2011;62:4833-42.

10. Hung HY, Shannon LM, Tian F, Bradbury PJ, Chen C, Flint-Garcia SA, et al. $\mathrm{ZmCCT}$ and the genetic basis of day-length adaptation underlying the postdomestication spread of maize. Proc Natl Acad Sci U S A. 2012;109: E1913-21.

11. Dong Z, Danilevskaya O, Abadie T, Messina C, Coles N, Cooper M. A gene regulatory network model for floral transition of the shoot apex in maize and its dynamic modeling. PLoS One. 2012;7:e43450.

12. Ku L, Tian L, Su H, Wang C, Wang X, Wu L, et al. Dual functions of the ZmCCT-associated quantitative trait locus in flowering and stress responses under long-day conditions. BMC Plant Biol. 2016:16:239.

13. Harmer SL. The circadian system in higher plants. Annu Rev Plant Biol. 2009; 60:357-77.

14. Haydon MJ, Mielczarek O, Robertson FC, Hubbard KE, Webb AA Photosynthetic entrainment of the Arabidopsis thaliana circadian clock. Nature. 2013:502:689-92.

15. Chiou TJ, Bush DR. Sucrose is a signal molecule in assimilate partitioning. Proc Natl Acad Sci U S A. 1998:95:4784-8.

16. Jang JC, Sheen J. Sugar sensing in higher plants. Plant Cell. 1994;6:1665-79.

17. Koch K. Sucrose metabolism: regulatory mechanisms and pivotal roles in sugar sensing and plant development. Curr Opin Plant Biol. 2004;7:235-46.

18. Rolland F, Baena-Gonzalez E, Sheen J. Sugar sensing and signaling in plants: conserved and novel mechanisms. Annu Rev Plant Biol. 2006;57:675-709.

19. Smeekens S. Sugar-induced signal transduction in plants. Annu Rev Plant Physiol Plant Mol Biol. 2000;51:49-81.

20. Capellades M, Lemeur R, Debergh P. Effects of sucrose on starch accumulation and rate of photosynthesis in Rosa culturedin vitro. Plant Cell Tissue Organ Cult. 1991;25:21-6 Plant Cell Tissue \& Organ Culture.

21. Hdider C, Desjardins Y. Effects of sucrose on metabolize pool sizes and ribulose-1,5-bisphosphate carboxylase/oxygenase activity in strawberry plantlets cultivated in vitro. 1994.

22. Achard P, Herr A, Baulcombe DC, Harberd NP. Modulation of floral development by a gibberellin-regulated microRNA. Development. 2004;131: $3357-65$. 
23. Cao D, Li Y, Wang J, Nan H, Wang Y, Lu S, et al. GmmiR156b overexpression delays flowering time in soybean. Plant Mol Biol. 2015;89:353-63.

24. Chavez-Hernandez EC, Alejandri-Ramirez ND, Juarez-Gonzalez VT, Dinkova TD. Maize miRNA and target regulation in response to hormone depletion and light exposure during somatic embryogenesis. Front Plant Sci. 2015;6:555.

25. Chen X. A microRNA as a translational repressor of APETALA2 in Arabidopsis flower development. Science. 2004;303:2022-5.

26. Jung JH, Seo YH, Seo PJ, Reyes JL, Yun J, Chua NH, et al. The GIGANTEAregulated microRNA172 mediates photoperiodic flowering independent of CONSTANS in Arabidopsis. Plant Cell. 2007;19:2736-48.

27. Zhou CM, Wang JW. Regulation of flowering time by microRNAs. J Genet Genomics. 2013;40:211-5.

28. Jung JH, Ju Y, Seo PJ, Lee JH, Park CM. The SOC1-SPL module integrates photoperiod and gibberellic acid signals to control flowering time in Arabidopsis. Plant J. 2012:69:577-88

29. Aung K, Lin SI, Wu CC, Huang YT, Su CL, Chiou TJ. pho2, a phosphate overaccumulator, is caused by a nonsense mutation in a microRNA399 target gene. Plant Physiol. 2006;141:1000-11.

30. Bari R, Datt Pant B, Stitt M, Scheible WR. PHO2, microRNA399, and PHR1 define a phosphate-signaling pathway in plants. Plant Physiol. 2006;141:988-99.

31. Lin Sl, Chiang SF, Lin WY, Chen JW, Tseng CY, Wu PC, et al. Regulatory network of microRNA399 and PHO2 by systemic signaling. Plant Physiol. 2008;147:732-46

32. Pant BD, Buhtz A, Kehr J, Scheible WR. MicroRNA399 is a long-distance signal for the regulation of plant phosphate homeostasis. Plant J. 2008:53:731-8.

33. Buhtz A, Springer F, Chappell L, Baulcombe DC, Kehr J. Identification and characterization of small RNAs from the phloem of Brassica napus. Plant J. 2008:53:739-49.

34. Liu TY, Chang CY, Chiou TJ. The long-distance signaling of mineral macronutrients. Curr Opin Plant Biol. 2009;12:312-9.

35. Mishra BS, Singh M, Aggrawal P, Laxmi A. Glucose and auxin signaling interaction in controlling Arabidopsis thaliana seedlings root growth and development. PLoS One. 2009;4:e4502.

36. Ni Z, Kim ED, Ha M, Lackey E, Liu J, Zhang Y, et al. Altered circadian rhythms regulate growth vigour in hybrids and allopolyploids. Nature. 2009;457:327-31.

37. Peng T, Lv Q, Zhang J, Li J, Du Y, Zhao Q. Differential expression of the microRNAs in superior and inferior spikelets in rice (Oryza sativa). J Exp Bot. 2011:62:4943-54

38. Ding D, Wang Y, Han M, Fu Z, Li W, Liu Z, et al. MicroRNA transcriptomic analysis of heterosis during maize seed germination. PLoS One. 2012;7: e39578.

39. Anders S, Huber W. Differential expression analysis for sequence count data. Genome Biol. 2010;11:R106.

40. Zhang Y. miRU: an automated plant miRNA target prediction server. Nucleic Acids Res. 2005:33:W701-4

41. Ren L, Tang G. Identification of sucrose-responsive microRNAs reveals sucrose-regulated copper accumulations in an SPL7-dependent and independent manner in Arabidopsis thaliana. Plant Sci. 2012;187:59-68.

42. Ashburner M, Ball CA, Blake JA, Botstein D, Butler H, Cherry JM, et al. Gene ontology: tool for the unification of biology. The gene ontology consortium. Nat Genet. 2000:25:25-9.

43. Hackenberg M, Shi BJ, Gustafson P, Langridge P. Characterization of phosphorusregulated miR399 and miR827 and their isomirs in barley under phosphorussufficient and phosphorus-deficient conditions. BMC Plant Biol. 2013;13:214.

44. Liu H, Yu H, Tang G, et al. Small but powerful: function of microRNAs in plant development. Plant Cell Rep. 2018;37:515-28.

45. Liu J, Samac DA, Bucciarelli B, Allan DL, Vance CP. Signaling of phosphorus deficiency-induced gene expression in white lupin requires sugar and phloem transport. Plant J. 2005:41:257-68.

46. Severson AR, Hubbard DD, Gibson DM. Changes in distribution of lipid, glucose-6-phosphate dehydrogenase and malate enzyme within the liver lobule of the rat during adaptive hyperlipogenesis. Anat Rec. 1973;175:231-41.

47. Lloyd JC, Zakhleniuk OV. Responses of primary and secondary metabolism to sugar accumulation revealed by microarray expression analysis of the Arabidopsis mutant, pho3. J Exp Bot. 2004;55:1221-30.

48. Fujii H, Chiou TJ, Lin Sl, Aung K, Zhu JK. A miRNA involved in phosphatestarvation response in Arabidopsis. Curr Biol. 2005;15:2038-43.

49. Zhu C, Ding Y, Liu H. MiR398 and plant stress responses. Physiol Plant. 2011; 143:1-9.

50. Nakaminami K, Matsui A, Shinozaki K, Seki M. RNA regulation in plant abiotic stress responses. Biochim Biophys Acta. 2012;1819:149-53.
51. Buhtz A, Pieritz J, Springer F, Kehr J. Phloem small RNAs, nutrient stress responses, and systemic mobility. BMC Plant Biol. 2010;10:64.

52. Liu J, Vance CP. Crucial roles of sucrose and microRNA399 in systemic signaling of $\mathrm{P}$ deficiency: a tale of two team players? Plant Signal Behav. 2010;5:1556-60.

53. Teotia S, Tang G. To bloom or not to bloom: role of microRNAs in plant flowering. Mol Plant. 2015;8:359-77.

54. Nie $S$, Xu L, Wang Y, Huang D, Muleke EM, Sun $X$, et al. Identification of boltingrelated microRNAs and their targets reveals complex miRNA-mediated floweringtime regulatory networks in radish (Raphanus sativus L.). Sci Rep. 2015;5:14034.

55. Gao J, Ge W, Zhang Y, Cheng Z, Li L, Hou D, et al. Identification and characterization of microRNAs at different flowering developmental stages in moso bamboo (Phyllostachys edulis) by high-throughput sequencing. Mol Gen Genomics. 2015;290:2335-53.

56. Xu MY, Zhang L, Li WW, Hu XL, Wang MB, Fan YL, et al. Stress-induced early flowering is mediated by miR169 in Arabidopsis thaliana. J Exp Bot. 2014;65: 89-101.

57. Spanudakis $\mathrm{E}$, Jackson $\mathrm{S}$. The role of microRNAs in the control of flowering time. J Exp Bot. 2014;65:365-80

58. Cui LG, Shan JX, Shi M, Gao JP, Lin HX. The miR156-SPL9-DFR pathway coordinates the relationship between development and abiotic stress tolerance in plants. Plant J. 2014:80:1108-17.

59. Luo Y, Guo Z, Li L. Evolutionary conservation of microRNA regulatory programs in plant flower development. Dev Biol. 2013;380:133-44.

60. Zhang X, Dou L, Pang C, Song M, Wei H, Fan S, et al. Genomic organization, differential expression, and functional analysis of the SPL gene family in Gossypium hirsutum. Mol Gen Genomics. 2015;290:115-26.

61. Aukerman MJ, Sakai H. Regulation of flowering time and floral organ identity by a MicroRNA and its APETALA2-like target genes. Plant Cell. 2003; 15:2730-41.

62. Wu G, Poethig RS. Temporal regulation of shoot development in Arabidopsis thaliana by miR156 and its target SPL3. Development. 2006;133: 3539-47.

63. Kim W, Ahn HJ, Chiou TJ, Ahn JH. The role of the miR399-PHO2 module in the regulation of flowering time in response to different ambient temperatures in Arabidopsis thaliana. Mol Cells. 2011;32:83-8.

64. Wang $\mathrm{G}$, Zhang $\mathrm{C}$, Battle $\mathrm{S}$, Lu H. The phosphate transporter PHT4;1 is a salicylic acid regulator likely controlled by the circadian clock protein CCA1. Front Plant Sci. 2014:5:701.

65. Graf A, Schlereth A, Stitt M, Smith AM. Circadian control of carbohydrate availability for growth in Arabidopsis plants at night. Proc Natl Acad Sci U S A. 2010;107:9458-63.

66. Graf A, Smith AM. Starch and the clock: the dark side of plant productivity. Trends Plant Sci. 2011;16:169-75.

67. Yazdanbakhsh N, Sulpice R, Graf A, Stitt M, Fisahn J. Circadian control of root elongation and $\mathrm{C}$ partitioning in Arabidopsis thaliana. Plant Cell Environ. 2011;34:877-94.

\section{Ready to submit your research? Choose BMC and benefit from:}

- fast, convenient online submission

- thorough peer review by experienced researchers in your field

- rapid publication on acceptance

- support for research data, including large and complex data types

- gold Open Access which fosters wider collaboration and increased citations

- maximum visibility for your research: over $100 \mathrm{M}$ website views per year

At BMC, research is always in progress.

Learn more biomedcentral.com/submissions 